\title{
Utilization of Internet as a Communication Media among Postgraduate Students of Ahmadu Bello University Zaria, Nigeria.
}

\author{
${ }^{1}$ Suleiman Hussaini, ${ }^{2}$ Abdulfatah Abdulrahim, ${ }^{3}$ Goshie Rhoda Wusa, Jimoh \\ ${ }^{4}$ Amina O., ${ }^{5}$ Hayatu M. Musa \\ 1,2,3,4 Kashim Ibrahim Library, Ahmadu Bello University Zaria, Nigeria. \\ ${ }^{5,}$ Department of Library and Information Science, Ahmadu Bello University Zaria, Nigeria.
}

\begin{abstract}
This research work was carried out to determine the Utilization of Internet as a Communication Media among Postgraduate Students of Ahmadu Bello University, Zaria. The population of the study is the postgraduate students of Ahmadu Bello University, Zaria. Survey method of the research and stratified random sampling was used for the study to select 550 postgraduate students for the study. However, 502 respondents responded to the questionnaires distributed. The data was presented and analyzed in tables and percentages. The research discovered that majority of the postgraduate students use internet services for their academic programs. It also reveals that utilization of internet has positive impact on postgraduate students and also has influenced the accessibility of online information usage of postgraduate students in Ahmadu Bello University, Zaria. This implies that most of the postgraduate students are internet users.
\end{abstract}

\section{Introduction}

The Internet has irrevocably invaded many aspects of daily life. What was once an obscure scientific research tool has blossomed into a communication plat form used by hundreds of millions of people. Telecom providers use the internet to carry critical voice communications. Banking institutions use it to provide access to account services and market trading. Airline tickets, hotel reservations and car rentals can all be booked with a click of the mouse. More users than ever depend on the internet to connect with family and colleagues using email, instant messaging, voice over IP, photo and video sharing services and online journals. The new technology and communication tools that are available today are much more powerful than those available even a few years ago. According to Abbottabad (2008) the channel for access and distribution of information and knowledge are much more diverse, they collapse the waiting time and provide more tools directly to the users. However, the internet as the world's largest network on information communication and services has changed the way we live and work. The advent if this technology has fundamentally transformed our lives the way the invention of automobile changed how our lives and cities looked and worked before. The maxim that "half the world does not know how the other lives" longer true.

As a result the internet is in transition, perhaps the greatest in its history. Originally the internet was concerned with text-based interfaces and keyboard control of remote computers, because of the limited informational capability of the network. It has evolved into a robust and sophisticated system with an informational capacity and computational power that its originator could have scarcely dreamed of. As a result, the internet components are increasingly becoming graphical in nature. High resolution graphics, formatted text, hyper-links, and mouse-driven interfaces are rapidly becoming the standard in much of the community. One interesting medium of today's communication in the world today is the invention of the internet. The internet is also an ideal environment that permits the effective integration of distributed and heterogeneous components, ensuring overall integrity in terms of functional and information inter-working. The popularization and accessibility of internet is changing the way postgraduate students of Ahmadu Bello University, Zaria search for information. The impact of internet on postgraduate students varied from institution to institution, but it is in constant evolution from a tool to connect people to information, to a social networking vehicle that is changing the way people in all countries communicate with each other.

Communication is the transmission of a message from a source to a receiver. For nearly 60 years now, this view of communication has been identified with the writing of political scientist Harold Lass well (1948). He said that a convenient way to desire communication is answer these questions:

- Who?

- Says what?

- Through which channel?

- To whom? 
- With what effect?

Expressed in terms of the basic elements of the communication process, communication occurs when a source sends a message through a medium to a receiver producing some effect. Obviously, communication requires the response of others. Therefore there must be a sharing (or respondence) of meaning for communication to take place.

The internet is a term applied to an electric network that permits access to thousands of computer network globally this is because it allows communication with millions of computer used for connection to the internet, a virtually limitless wealth of resources is available for everyday gender, education, occupation, income and even geographical region, with some of the generals conclusions being that males postgraduates students are more likely to use the net than their female counter part, people higher socio-economic status are more likely to use the last few years and is available in over one hundred countries(World Almanac 1997). It also provides opportunities for inquiry (lectures) can network, study and collaborate with others around the world. There were approximately 64 million users in 1998(Mediamark, 1999) According to data reported from the emerging Technologies Research Group nearly three quarters of internet users consider the internet indispensable and 60 percent of those who use the internet for business purpose daily(Emerging Technologies Research Group 1997) there is an additional 55 million adults who indicates either that they intend to begin using the internet in the next year or that they would like to learn more about it. This suggest the number of users likely to grow substantially in the future(Emerging Technology Research Group 1997) The real importance of the internet is also available I languages apart from English and many list news group cater to non- English speakers

\section{Historical Background Of Postgraduate Studies In Ahmadu Bello University, Zaria.}

The Ahmadu Bello University was established in October 1962. The University presently has a population of about 25,000 undergraduate and 6,000 postgraduate students drawn from various parts of Nigeria, from other African countries as well as from other parts of the world. With twelve faculties, one Postgraduate School, five Research Institutions and six specialized centre's, the University offers a wide range of opportunities for postgraduate research in Administration, Agriculture, Arts, Education, Engineering, Environmental Design, Law, Medicine, Pharmaceutical Science, Physical Sciences, Biological Sciences, Social Science and Veterinary Medicine.

The Postgraduate School was established in 1980 to enable the University achieve a higher degree of emphasis and coordination in its postgraduate training and research. The school was also charge with the responsibility of assisting departments improve training programmes to provide qualified manpower for the University, other Universities, private sector, institutions of higher learning, public corporations and parastatals, federal and state governments. Recently, The Ahmadu Bello University along with the University of Ibadan and the University of Nigeria Nsukka have been charge with the responsibility of producing the needed manpower for other tertiary Institution hence they should place more emphasis on postgraduate studies.

\section{Statement Of The Problem}

Internet component gateway has grown very high for a new lease of live for our postgraduate students and educational system courtesy of internet. Internet component are specifically valuable to undergraduate students, lectures, and those who are interested in using it. Internet allow greater flexibility while communicating because they do not need to remain at a fixed location, such as home, classroom of office, the internet are also useful in communication in remote locations, postgraduate students can benefit from using the internet on research findings in any field of human endeavors.

However, the internet can serve people in educational sector in many ways but presented. The vast educational materials on the internet in terms of research and project finding can be easily tapped and postgraduate students can use the devices to improve the quality of information that is used in research work. If postgraduates have access to the communication media particularly the internet component like E-mail and World Wide Web, they can use it to educate themselves and be current in there are of specialization.

But contrary to the aforementioned advantages that can be tapped from the internet by postgraduate students, it is important that most postgraduates' students do not know how to use the internet.

The research intends to investigate the level at which postgraduate students use the internet component for the purpose of learning and communication.

\section{Objectives Of The Study} following.

The purpose of this study is aimed at unveiling the variables that are most inherent at achieving the

- To identify the type of internet services those postgraduate students of Ahmadu Bello University uses.

- To determine how frequent the postgraduate students uses the internet. 
- Examine the accessibility of the internet by postgraduate students of Ahmadu Bello University in their academic programme.

- To identify the problems encountered by Postgraduate of Ahmadu Bello University, Zaria when using the internet

\section{Research Questions}

The study was guided by the five research questions and they are as follows:

- What type of internet services are used by postgraduate students of Ahmadu Bello University Zaria?

- How frequent do the postgraduate students of Ahmadu Bello University use the internet while online?

- How assessible is the internet to their academic programmes.

- What are the problems encountered in the process of using the internet?

\section{Literature Review}

Tiamiyu (2000:126) indicate that the internet is a computer networks interconnected by the various telecommunication systems of various countries globally that store, transfer, or deliver messages and computer files inform of electronic signals twenty four hours daily. Gould(2004:par 13-14), regards the internet as the convergence of all channels which due to its "packet nature" does not differentiate between any channels in transferring data.

Brown (2000) sees Internet as the two edge sword of that leading the process of globalization having the potentials of wounding those who don't quickly enough grasp how to use it by leaving them ever further behind, but providing unprecedented benefits for those, with the courage and willingness to grasp its potentials to drive change.

In the words of Singha (1986) he said Communication is of two concepts that have been defined in various ways by communication scholars and social scientists. From Singh's Perspective Communication is the transfer of information from one place to another in a desired direction with an expectation to bring about a desired effect.

Some scholars believe Communication has to be two way to be effective Ngugi (1995) citing Oliver(1993) says communication is the transfer of idea of knowledge in ways that enable the recipients to understand, react to and act upon the information received. Mercado (1992) feels Communication is a process of Sharing messages between a source and a receiver either directly or through channel. He also sees Communication as the process of transmitting information, ideas and knowledge from a source to a receiver or several audience through a medium or several media with the possibility of feedback.

Ebersole (2000:4) argued that the diversity of content is much greater for the World Wide Web (WWW) than for traditional media. While television, radio and to a lesser degree print media are subject to regulatory and societal scrutiny, the WWW is virtually unregulated. Because of this, the WWW literally has something for everyday. The fact that this range of material is available at school, library and workplace and home would suggest that potential users of internet may exceed those provided by other Media.

Payne further expands on the influence of internet and technologies on our age and world when he opines that:

"New communication technologies such as the internet, voicemail Cellular telephones, pagers faxes and two-way video have changed the way we live, learn and work. Each of the new technologies permit us to communicate with more people regardless of where we are. While technology has made the word smaller, communication more rapid access easier. It has also created a new set of problems and New issues concerning the use of the gadgets available to us' Payne (2001:181)."

Ryan's (1999) survey of Public Relations Society of America (PRSA) members indicates that 99 percent use internet and World Wide Web (WWW) regularly. They use it for surveillance of other companies, access to external databases and for examining the activities of government.

According to a paper by the Food and Agriculture organization of the United Nations (FAO) the internet brings new information resources and can open up new communication channels for rural communities. It presents the means for bridging the gaps between development professional and rural people through the initiation of interaction and dialogue. They also believe that the internet can foster new alliances and interpersonal networks together with literal and cross sector links between organizations. Most importantly it has the potential of supporting mechanisms that enable the articulation and sharing of information on needs and local knowledge (Richardson, 1997)

Hajiya Maryam Inna (2007) refers Media to all the channel of communication both print and electronic. She believes that media enable a person to communicate to large number of people to a social or public cause and objective.

Numerous scholars have attested to the seemingly limitless powers and influence of the internet over other forms of information communication media. According to Roberts, Wanta, and Tzong (2002:452), "the Internet has drastically changed the ways in which some individuals receive news and information." And 
according to Baran (2002:163, "the Internet and the World Wide Web provide readers with more information and more depth and with greater speed, than the traditional newspapers".

Baran (2002:68) further sees internet as a global network of inter-connected computers that communicate freely and share and exchange information.

Some other schools of thought see media as an instance of an attempt to incorporate the mass society critique and put it to use from within a Marxist framework. Mass society society which having a pre-degree reaching back into mid-nineteenth century, has view the development of media pessimistically as a constituting a threat. This school of thought also believe that the media is seen to be constituting threat either the integrity of elite cultural values or the viability of the political institutions of democracy.

Some scholars are on the opinion that media tended to focus on negative trends in the polity and played down the achievement of the government. Ajah, Nweke (2006) believes that the media will be abdicating its responsibilities if it fails to report issues that the national and the international importance in the name of national interest. She also believes that the media is expected to promote issues that concerns the people and not devote so much concerning the bickering among politicians

According to Alhaji Baba Halilu Dantiye believes that Media pass information to targeted audience. They act as filters and decide what is important and what is actually reported.

According to Irvine of Georgetown University cited in Fleur and/Denin (2002:219) argued that the Internet is more than a network of computers. He further extended the meaning of Internet earlier given that: the internet has three components:

a. worldwide computer system using a common means of linking hardware and transmitting digital information. b. a community of people using a common communication technology, a globally distributed system system of information.

Morris and Ogan (1996) both researchers from Indiana University argued that "Internet as a whole should be considered as a mass medium." They maintained that the communication theorist must disregard the researchers' potential of the internet, as this could render their communication theories less useful. It is quite evident that communication has changed television, newspapers and radio. It is therefore expected that the new technology of internet would also pose the same change and problems.

However, he Internet, an international network of computers has introduced new dimension into communication. As a means of communicating through the atmosphere, the Internet has succeeded in actualizing Marshall McLuhan's ideas of a global village has turned the world into a sitting room. The Internet is comprised of a bunch of interconnected networks that allow communication with Millions of Library users and access to resources from around the world. Internet is increasingly dominating the world and many activities have benefitted education and broaden range of other human activities. The Internet is also called or referred to as virtual library. It does not only offer access to many libraries but it gives access topics of special internet using website.

Over the years, the use of the Internet has become widespread. Internet component are:

- Electronic mail: Electronic mail, or e-mail, is used to communicate with other Internet users, regardless of where they are on the Internet. E-mail is fast and has amazing flexibility. With e-mail, it is possible not only to send messages, but also to execute programs and analyses on remote computers, retrieve data and files, and subscribe to news and informational services.

- World Wide Web: The Web is the newest of the internet components and is rapidly becoming the most popular. Resources and Information displayed on graphical-based Web browsers appear much like a newspaper or magazine page. Text, images, video, and sound can be presented. Information is linked together, much like a web (hence the name). This web-like linkage of information makes it possible to browse through vast amounts of information without specifying a starting point or a destination.

- Telnet: Telnet is based on UNIX, a multi-user/multitasking operating system often used on computer workstations. Through Telnet, a remote computer can be used to operate a distant computer almost transparent, as if the distant computer and the remote computer were one and one and the same. This allows the user of the remote computer to interactively control the distant computer to perform analyses data or images or to execute programs.

- Internet Relay Chat: Internet Relay Chat or IRC is simply an interactive (and live), online discussion group. When using IRC, real-time conferencing is possible. IRC is broken down by channels that have specific topics for discussion. As IRC is a component of internet, it is possible to create specific topics channels flexible for focused discussions on a topic, or to create broader, more open channel.

- File Transfer Protocol (FTP): is used to download files from an Internet site to a user's computer. The FTP application is often automatically invoked when a user downloads an updated version of a piece of software. Applications such as FTP have been integrated with the World Wide Web, making them 
transparent so that they run automatically without requiring users to open them. When a Web browser encounters a URL that begins with ftp: // it automatically uses FTP to access the item.

- Network News discussion groups (newsgroups): originally part of the Usenet network, is another form of online discussion. Thousands of newsgroups exist, on an extremely wide range of subjects. Messages to a newsgroup are not sent directly to each user. Instead, an ordered list is disseminated to computers around the world that run news server software. Newsgroup application software allows a user to obtain a copy of selected articles from a local news server or to use e-mail to post a new message to the newsgroup. The system makes newsgroup discussions available worldwide.

- Voice over IP (VoIP) allows individuals and businesses to make phone calls over the Internet. Low-cost services (some of them free) often transfer calls via personal computers (PCs) equipped with microphones and speakers instead of the traditional telephone handset. But a growing number of services operate outside the PC, making calls via a special adapter that connects to a traditional telephone handset. The calls still travel over the Internet, but the person using the special adapter never has to turn on his or her computer. Thousands now use such VoIP services in lieu of traditional phone service. VoIP services are not subject to the same government regulation as traditional phone service. Thus, they are often less expensive.

- Chat and Instant Messaging: Chat program allow users on the internet to communicate with each other by typing in real time. They are sometimes included as features of a website where user can log into the chat room to exchange comments and information about the topics address on the site. Chat may take other more wide range for example the American online is well known for sponsoring a number of topics chat room. The internet can also perform the following functions such as:

- Research and Information: This function of internet helps to provide information in any subjects, using browsers and search tools.

- News: It also helps a researcher or individual to stay current on politics, weather, entertainment, sport and financial news.

- Download files: The internet helps to get software, music and documents such as e-books

- $\quad \boldsymbol{E}$-shopping: It enable individual to price anything from plane tickets to cars, order anything from books to sofas.

- Financial Investment: It enables an individual to the following services such as investing, banking and bill paying online.

- Auctions: The internet can be used to sell old stuff, acquire more stuff with online auctions

- Distance learning: Attend online lectures, have discussions, write research papers and earn degree.

- $\quad \boldsymbol{E}$-bank: It helps to connect with coworkers, buy supplies, support customers, and conduct negotiations.

- Carrier Advancement: The internet helps to search for jobs listings, post discussions, write research papers and earn degree. Briank.K Williams and Stacey.C. Sawyer(2011)

\section{Limitations Of Internet}

a) Internet Hacking: Hackers penetrate into people's internet program and infect them with their own program.

b) Internet Piracy: It involves the illegal copying of internet programs with the aid of making money out of it.

c) Promotion of Immorality: Many youths of today engage themselves in watching Websites where pornography is promoted. This usually leads to moral decadence.

d) Insufficient Search: Even the most efficient of the search engines covers less than a sixth of all public available pages.

The main aim of Communication Media is for information and entertainment, although it can be served in different proportions, internet was a success most of all in two sphere, Pornography and Music. The internet help to the myth new hopes, especially in ash era of virtual reality. Unification was a tool, which diminished difference in industrial societies. The internet however, has been many years exclusively academic habits an example can be copyright universities never let capitalists' version of the copyrights to intellectual property imposed on them and up till today every library hardly cope with it.

\section{Methodology}

This design of this study is survey research method. This is because The survey method adopted was due to large population of research that is been studied and detailed collection of data on the Utilization Internet as a Communication Media among Postgraduate students of Ahmadu Bello University, Zaria. The instrument used for the data collection is questionnaire. Copies of the questionnaire were administered to the respondents by the researcher at different time in both campuses. On the whole a total of 550 copies of questionnaire were distributed by the researcher and 502 copies were completed and returned. The data generated for the study was analyzed using frequency tables and percentages. 


\section{Results And Discussions}

The findings of the study are presented under the following sub-sections in the same manner the researcher questions were phrased, namely: Internets services, frequent use of internet, academic programmes, problems encountered and discussions on the way forward.

Types of Internet Services

\begin{tabular}{|l|l|l|}
\hline Internet Services & No. Of Respondents & Percentage \% \\
\hline Website browsing & 310 & $61.8 \%$ \\
\hline E-mail & 146 & $29.1 \%$ \\
\hline File Transfer Protocol & 30 & $6.0 \%$ \\
\hline Telnet (Chat Services) & 10 & $2.0 \%$ \\
\hline None of the above & 0 & $0 \%$ \\
\hline Total & $\mathbf{5 0 2}$ & $\mathbf{9 9 \%}$ \\
\hline
\end{tabular}

Table 1 shows that 310(61.8\%) and 146(29.1\%) majority of the respondents indicated they use both website browsing and E-mail, While File Transfer Protocol and Telnet (Chat Services) 30(6.0\%) and 10(2.0\%) also indicated that they don't use the services frequently. This implies that, majority of the respondents make use of Website browsing more often than any other internet services.

Frequent Use Of The Internet

\begin{tabular}{|l|l|l|}
\hline Frequent Use Of Internet & No. Of Respondent & Percentage\% \\
\hline Daily & 390 & $77.7 \%$ \\
\hline Monthly & 110 & $21.9 \%$ \\
\hline None of the above & 2 & $0.4 \%$ \\
\hline Total & $\mathbf{5 0 2}$ & $\mathbf{1 0 0 \%}$ \\
\hline
\end{tabular}

The table 2 shows that majority of the respondents make frequent use of the internet on daily bases with $(77.7 \%)$ while the least frequent with those that make frequent use of the internet on monthly bases is $21.9 \%$ respectively while $0.4 \%$ do not frequently use the internet at all. This implies that most of the postgraduate students are internet users.

Accessibility Of The Internet

\begin{tabular}{|l|l|l|}
\hline Access To Internet & No. Of Respondents & Percentage \% \\
\hline Not accessible & 31 & $6.2 \%$ \\
\hline Accessible & 73 & $14.5 \%$ \\
\hline Very accessible & 398 & $63.4 \%$ \\
\hline Total & $\mathbf{5 0 2}$ & $\mathbf{1 0 0 \%}$ \\
\hline
\end{tabular}

Table 3. above shows that 31(6.2\%) respondents had no access to the internet, while 73(14.5\%) and $398(63.4 \%)$ shows that they had access to the internet respectively. This implies that majority of the postgraduate students in Ahmadu Bello University have access to the internet.

Academic Programs

\begin{tabular}{|l|l|l|}
\hline Types Of Academic Programs & No. Of Respondents & Percentage \% \\
\hline $\begin{array}{l}\text { To communicate with other postgraduate } \\
\text { students }\end{array}$ & 45 & $9.0 \%$ \\
\hline For reading news & 53 & $10.6 \%$ \\
\hline To source for materials & 400 & $79.7 \%$ \\
\hline None of the above & 4 & $0.8 \%$ \\
\hline Total & $\mathbf{5 0 2}$ & $\mathbf{1 0 0 \%}$ \\
\hline
\end{tabular}

Table 4. shows that $(9.0 \%) 45$ of the respondents indicated that they use the internet to communicate with other students while 53(10.6\%) and 400(79.7\%) indicated that they use the internet for reading news and to source for materials. $4(0.8 \%)$ of the respondents indicated that they neither use it for communication with other postgraduate students for reading news nor to source for materials. This implies that majority of the respondents particularly the postgraduates students use the internet to source for materials for their academic programs and reading news.

Problems Encourtered In The Use Of Internet

\begin{tabular}{|l|l|l|}
\hline PROBLEMS & NO. Of Respondnets & Percentage \% \\
\hline Slow response & 190 & $37.9 \%$ \\
\hline Inability to locate information & 9 & $1.8 \%$ \\
\hline Poor browsing time rate & 98 & $19.5 \%$ \\
\hline Inadequate power supply & 205 & $40.8 \%$ \\
\hline Total & $\mathbf{5 0 2}$ & $\mathbf{1 0 0 \%}$ \\
\hline
\end{tabular}


Table 5. shows that the respondents accepted all the items as internet problems. The four most accepted problems are slow response rate 190(37.9\%) and Poor browsing time rate 98(19.5\%) and 205(40\%) inadequate power supply which is a very great problem in Nigeria. Respondents also complained of the inability to locate or find what they want. While $9(1.8 \%)$ of the respondents indicated that they neither experience any of the problems. This implies that the majority of the Postgraduate students do encounter problems when using the internet.

\section{Discussions}

The findings from this study are quite revealing. From the study, it was discovered that majority of the postgraduate students represented by $61 \%$ (310) of the respondents use virtually all the internet services to achieve their aim. This is not surprising looking at the global information trend.

The findings also discovered that most of the postgraduate students $61.5 \%$ (310) who frequently use the internet, use it more on daily bases for their various works.

Majority of the postgraduate students representing 398(63.4\%) indicated that internet is accessible. However, most of them have access to internet using Ahmadu Bello University, Zaria fiber optics, Ahmadu Bello University wireless and their personal modem and phones with internet facilities and services, the library and internet café also inclusive.

It was also discovered that majority of the postgraduate students make use of the internet services particularly the Website browsing more than any other internet services for research purposes, sending e-mails etc. The type of information resources mostly consulted online by the postgraduate students are e-journals, ebooks etc.

However, the study also reveals some of the problems encountered by the postgraduate students of Ahmadu Bello University, Zaria when using the internet as;

a. Slow response

a. Inability to locate information

b. Poor browsing time rate

c. Inadequate power supply

\section{Conclusion/Recommendations}

It is evident from the study that the researcher was able to have an insight on the Utilization of Internet as a Communication Media by postgraduate students of Ahmadu Bello University, Zaria. However, the study reveals that internet utilization has a significant impact on postgraduate students of Ahmadu Bello University, Zaria. This implies that majority of the postgraduates students are internet users. The study reveals that most frequent use of internet services by the postgraduate students are Web browsing (WWW) and e-mail.

The study shows that internet is accessible to postgraduate students in Ahmadu Bello University, Zaria. The research also shows that most problems encountered by the students are slow response, inability to locate up to date information, poor browsing rate and inadequate power supply. Therefore, in view of this study, the researcher concluded that the utilization of internet as a communication media by postgraduate students of Ahmadu Bello University, Zaria is good.

\section{Recommendations}

Against the background of the findings and conclusions drawn from the study, the following recommendations have been put forward to improve on the Utilization of Internet as a Communication Media among Postgraduate Students of Ahmadu Bello University, Zaria.

1. The Postgraduate school of Ahmadu Bello University, Zaria should take all the necessary steps in ensuring that the problem of slow response rate, inability to locate information and poor browsing rate are addressed.

2. The Postgraduate school should encourage their students to personally purchase internet modems and mobile phones with internet facilities and services to enhance their access to variety of online services so as to improve the quality of their research and not depend solely on fibre optics..

3. The Postgraduate school of Ahmadu Bello University, Zaria should train their students to be literate either through organizing workshops on Information Technology and internet utilization.

4. The Postgraduate school should also encourage Postgraduate students to fully utilize the fibre optics internet facilities found in our classes, offices, lecture theatres and our library.

It is expected that if these suggestions and recommendations are adopted by the School of Postgraduate studies, Ahmadu Bello University, Zaria. Adequate utilization of the internet will serve as a major strategy for developing and improving Postgraduate students in Ahmadu Bello University, Zaria. 


\section{References}

[1]. Ahmadu Bello University, Zaria. Postgraduate 2010-2013 School of Postgraduate Studies Prospectus. (2011/2012 Session)

[2]. Adedina. F.A, Adeniyi K.A and Bolaji.E.T (2007) The Internet as Mass Communication: Ebenezer Soola Conference on Communication proceedings.

[3]. Akuezuilo, E.O (1993) "Research Methodology and Statistics" Nuc Centi: Nig; Publishers, Anambra, $2^{\text {nd }}$ ed. Pp 43-60

[4]. Baran, S.J (2002) Introduction to Mass Communication: Media literacy and Culture. ( $2^{\text {nd }}$ ed)Boston: McGraw.

[5]. Brown.M.M (2000) The Challenge of Information and Communication Technology for Development. Tokyo: UN

[6]. Busha, Cha and Harter (1980) Research Method Librarianship Techniques and Interpretation, New York; Academic Press.

[7]. Byron, Reeves and Clifford Mass (1996) The Media Equation New York, Cambridge University Press, Pp. 8-10.

[8]. Defleur, M.Land Denis, E.E (2002) Understanding Mass Communication: A Liberal Arts Perspective Boston: Houghton Mifflin Company. Ebenezer Soola Conference on Communication Proceedings

[9]. Ebersole. (2000) Uses and Gratifications of the Web among Students in Journal of Mediated Communication 6(11) online.

[10]. Flickenger, R (2006) How to accelerate your internet, INASP/ICTP: October 2006. Pp1-2 Glossary of Terms used Internet and Distance Education. Pp.4; http://www.teward.com/archives/glossary. Retrieved Oct 2013.

[11]. H.M. Deitel, P.J. Deitel and A.B.Goldberg (2002) Internet and Worldwide Web "How to Program" Third edition: Pearson Prentice Hall.

[12]. Kerlinger, F.N (1073) Foundations of behavior research, New York Holt, Leonard Peruski Jr and Anne Harwood Peruski (1997) The Internet and the New Biology Microsoft Encarta Reference Library 2007

[13]. Media, Culture and Society journal, Vol.26 No.5, September 2004, Journal of Development Communication (JDP)

[14]. Media Culture and Society, Vol. 28: No 5. September (2006), Journal of Development Communication

[15]. Mercado.C.M. (1992) "Development Communication Management" Journal of Development Communication Vol.2. No 2. Pp 1325.Microsoft ® Encarta ® 2009 .

[16]. Morris, Merrill and Ogan Christine (1996). "The Internet as a Mass Medium" Journal of Communication" 46(1): 35-50.

[17]. Ngugi, M. (1995) "Development Communication: A clarification of construct" Africa MediaReview. Vol. 9, No.2 Pp 1-13

[18]. Nwana, O.C (1992) "Introduction to Educational Research Methodology, Ilorin Pp 122-124.

[19]. Oliverra, M.C.B (1993) "Communication Strategies for Agricultural Development in the Third World" Media Asia, Vol.20, No 2. Pp. 102-108.

[20]. Payne. J (2001) Application Communication for Personal and Professional Contexts Topeka: Clark Publishing.

[21]. Richardson, D. (1997). The Internet and Rural and Agricultural Development: An Integrated approach. Rome: FAO.

[22]. Roberts, M. Wayne W. and Tsong-Horng.D. (2002) "Agenda Sitting and Issue salience Online" Communication Research. 29 (4) Pp 452-465

[23]. Sinha. A.K (1986) "Communication and Rural Development” The Indian Scene. Gazette, Vol.38 Pp 59-70.

[24]. The Nigerian Journal of Communication: Patterns of Utilization of the Internet and World Wide Web by Nigerian Newspapers Pp $156-163$.

[25]. Williams,K Briank and Sawyer C. Stacey.(2011) Using Information Technology: A practical Introduction to Computers and CommunicationNinth Edition: M.C Graw: Hill, Newyork.World almanac 1997 